\title{
Structure Analysis and Design of Automobile plastic clutch pump body based on friction welding
}

\author{
Jing Sheng ${ }^{1,2, a}$, Aamir Sohail $^{2}$, Mengguang Wang ${ }^{2}$ and Zhimin Wang ${ }^{2}$ \\ ${ }^{1}$ Fujian Key Laboratory of Advanced Design and Manufacture for Bus\$Coach, Xiamen University of Technology, 361024 Fujian Xiamen, \\ China \\ ${ }^{2}$ Fujian Collaborative Innovation Center for R\&D of Coach and Special Vehicle, Xiamen University of Technology, 361024 Fujian Xiamen, \\ China
}

\begin{abstract}
In order to realize the need for lightweight automobiles through replacing steel with plastics, the research and development of the plastic clutch pump body based on the friction welding was carried out. For the clutch pump body connected by friction welding process between the upper pump body and the lower pump body, the technical requirements of pressure $14 \mathrm{MPa}$ and durability (high temperature $7.0 \times 10^{4}$ times, room temperature $7.0 \times 10^{5}$ ) are required. The structure type of the upper and lower pump bodies of the end face welding type was proposed. Through the static analysis of the pump body and weld and the mechanical analysis under the working condition, the structure of the clutch pump body (upper and lower pump body) was determined. According to the established welding process, the pressure of the clutch pump body is more than $15 \mathrm{MPa}$, and the number of high-temperature durable circulation and the number of room temperature durable circulation also reached $7.2 \times 10^{4}$ and $7.3 \times 10^{5}$ times respectively. The results show that the structural design of a clutch pump body meets the design requirements.

Keywords: Plastic clutch pump body; Rotating friction welding; Welding surface structure; Finite element analysis; Durability
\end{abstract}

\section{Introduction}

As plastic parts can meet the requirements of lightweight and satisfy the safety and environmental protection standards, automobile plastic parts emerge at the right moment. "Replacing Steel with Plastics" has become the trend of parts development in the automotive industry. The plastic clutch master pump ( Fig. 1a) is an important component of the automobile clutch control system. Its function is to convert the force input by the clutch pedal into hydraulic pressure and output it to the clutch slave cylinder, which converts the hydraulic pressure into thrust and pushes the clutch release bearing to realize the clutch separation [1]. As the key part of the clutch master cylinder, the clutch pump body (Fig. 1b) has some problems for example air leakage and short service life, so the plastic clutch master cylinder has not been widely used up to now. Therefore, in order to provide a reference for its design, it is necessary to analyze the structure of the pump body of the plastic clutch considering the welding process.

Plastic processing technology expands the manufacturing process of auto parts ${ }^{[2-4]}$. In rotary welding, Tappe et al. ${ }^{[5]}$ analyzed the effect of welding parameters and material properties on the temperature of the welding zone in plastic rotary welding and discussed the influence of welding parameters on the quality of welding seam. Stokes ${ }^{[6]}$ studied the change of viscosity of liquid plastic

\footnotetext{
a Corresponding author: shengqqqqjing@163.com
}

during the steady melting process of rotary welding. Phadke ${ }^{[7]}$ introduced the rotary welding technology of connecting spherical or cylindrical plastic parts by friction welding.

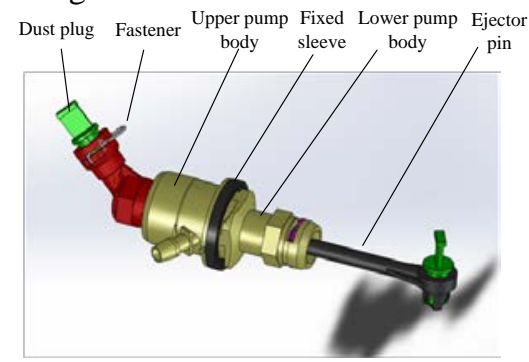

Figure 1a. Structure of a clutch master cylinder

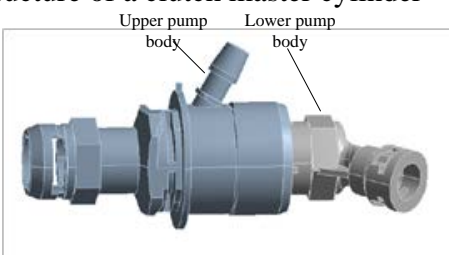

Figure 1b. Clutch pump body

Figure 1. Clutch total pump structure and clutch pump body

So far, no relevant report on the design of a clutch pump body (Fig. 1) mentioned in this paper has been seen. Although the above research has certain reference value, it is not enough to guide the structural design of a clutch 
pump body using friction welding. Therefore, this paper puts forward the structural design scheme of the clutch pump body based on the friction welding technology. Through the strength analysis of the clutch pump body and its weld, as well as the test verification, the correctness of the structural design of a clutch pump body is clarified.

\section{Structure Design of Clutch Pump Body}

The design requirements of the clutch pump body are: it can bear $14 \mathrm{MPa}$ pressure under normal temperature; it can work $7 \times 10^{4}$ times under $100{ }^{\circ} \mathrm{C}$ high temperature and 3.5 Mpa pressure; it can work $7 \times 10^{5}$ times under normal temperature and 3.5 Mpa pressure.

\subsection{Mechanical model of the working state of a clutch pump body}

In the elastic state, the inner wall of the pump body bears radial stress, axial stress, and tangential stress. For the thick wall pump body with internal pressure, the most dangerous point is the inner wall. The three principal stresses of dangerous points are:

$$
\begin{aligned}
& \sigma_{1}=\sigma_{t}=\frac{K^{2}+1}{K^{2}-1} p \\
& \sigma_{2}=\sigma_{a}=\frac{1}{K^{2}-1} p \\
& \sigma_{3}=\sigma_{r}=-p
\end{aligned}
$$

In the formula, $K=D / d$, $\sigma \mathrm{r}$ is the radial stress, $\sigma \mathrm{t}$ is the tangential stress, $\sigma a$ is the axial stress, D is the outer diameter of the pump body, $\mathrm{d}$ is the inner diameter of the pump body, $\mathrm{P}$ is the internal pressure of the pump body. When the pump body is in normal operation, the cavity is filled with hydraulic oil, and the oil pressure is 3.5 MPa. Considering the design requirements of a clutch pump, set the oil pressure to $14 \mathrm{MPa}$ (safety factor is 4). According to the first and third strength theory, the mechanical model of the clutch pump is:

$$
\begin{aligned}
& \sigma_{1}=\frac{K^{2}+1}{K^{2}-1} p \leq[\sigma] \\
& \sigma_{1}-\sigma_{3}=\frac{2 K^{2}}{K^{2}-1} p \leq[\sigma]
\end{aligned}
$$

In the formula, $[\sigma]$ is the allowable stress of the material.

\subsection{Material selection of clutch pump body}

PAMXD6 has good mechanical properties (Tab. 1), heat resistance, oil resistance, weak acid resistance, alkali resistance, good shock absorption, and noise reduction, therefore it is widely used in automobiles, electrical equipment, and mechanical parts. Based on the technical requirements of the clutch pump body and consideration of production cost, PAMXD6 is selected as the material for the manufacturing clutch pump body.

Table 1. Performance Parameters of PAMXD6 Material

\begin{tabular}{|c|c|}
\hline Parameter & Value \\
\hline Density & $1.70 \mathrm{~g} / \mathrm{cm}^{3}$ \\
\hline Tensile strength & $255 \mathrm{MPa}$ \\
\hline Elongation at break & $1.9 \%$ \\
\hline Modulus of elasticity & $20000 \mathrm{MPa}$ \\
\hline Rockwell hardness & $100 \mathrm{M}$ \\
\hline
\end{tabular}

\subsection{Structure design of welding surface of clutch pump body (upper and lower pump bodies) considering the friction welding process}

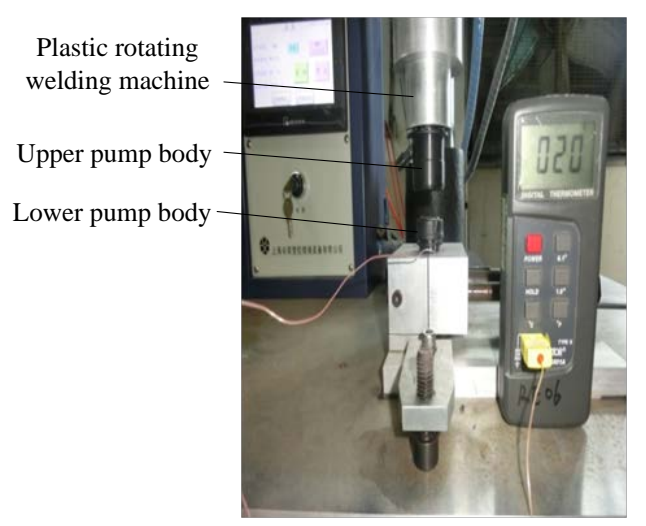

Figure 2. Welding Equipment of the Pump Body of the PlasticMade Clutch

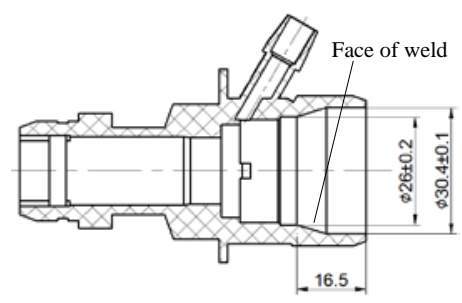

Figure 3a. Cylinder welded upper pump body

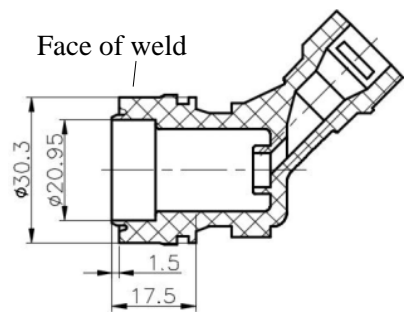

Figure 3b. Cylinder welded lower pump body Figure 3. Plastic clutch pump body with cylindrical welding style 


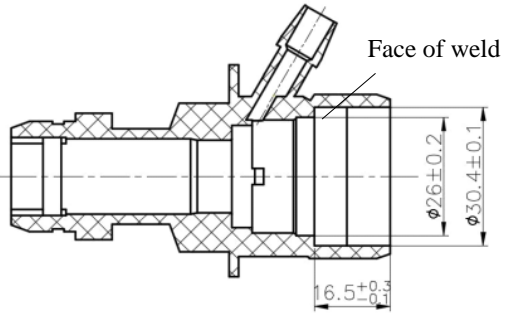

Figure 4a. End welded upper pump body

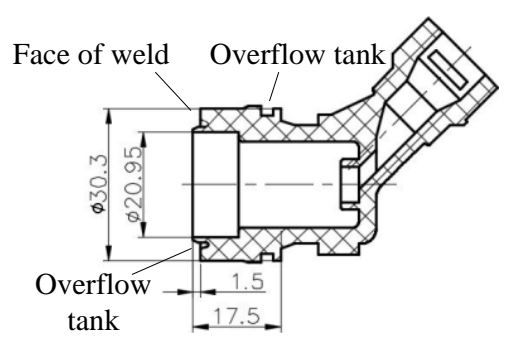

Figure 4b.End welded lower pump body

Figure 4. Plastic clutch pump body with end face welding style

The process of rotary friction is: contact, press and rotate the welding surfaces of the two plastic parts, resulting in the friction heat to melt the contact surfaces; after the rotation stops, the pressure is maintained until the melted materials solidify, as shown in Fig. 2. When designing the welding surface, the welding surface should be simple in structure and compact in space. According to the functional requirements of the clutch pump, material characteristics and mechanical model of the clutch pump body at work, combined with the characteristics of rotary friction welding, the structural types of the upper and lower pump bodies of cylinder welding type (Fig. 3) and end welding type (Fig. 4) are proposed. Considering the blown off of plastic debris during welding, the overflow tank is set up on the lower pump body.

Obviously, the lower pump body structure of the two welding methods is the same, and the upper pump body is different. When the cylinder welding type is adopted, the main shaft drives the upper pump body. Due to the elastic deformation of the material, the inner conical surface of the upper pump body contacts with the welded cylindrical surface of the lower pump body; when the end welding type is adopted, the inner end surface of the upper pump body contacts with the outer end surface of the lower pump body. When the upper pump body rotates with the main shaft of the welding machine, the two welding surfaces of the upper and lower pump body begin to be welded. The melted plastic fills the welding surfaces of the upper and lower pump body and finally connects them into a pump body assembly.

It is not difficult to see that when cylinder welding is adopted, the contact stress between the inner cone welding surface of the upper pump body and the cylinder welding surface of the lower pump body changes in gradient. With the melting of the plastic on the welding surface, the contact stress of the welding surface gradually decreases. Even if there is certain stress on the welding surface, the temperature generated will not only prevent the contact surface from melting ${ }^{[8]}$, but also cause the debris to mix into the molten plastic during friction. On the way of end face welding, when the welding surface of the inner end face of the upper pump body contacts with the welding surface of the outer end face of the lower pump body, the pressure stress is uniform, and the friction heat generated per unit time is the same, which ensures the stability of the plastic melting process.

Five groups of samples were welded according to the cylinder welding method and the end face welding method, so as to verify the above analysis. In order to check the welding quality, the samples were cut. It found that the welding seam of the sample after cylinder welding is uneven to different degrees, and the welding seam is obviously mixed with debris (see Fig. 5a); However, the welding seam of the end face weldment is even and flat (see Fig. 5b), and the debris in the weld joint is not obvious. In order to further verify the welding quality of the two welding methods, 10 samples of the above two methods were tested for the weld strength. The results showed that the average pressure of the clutch pump body manufactured by the cylinder welding method was $4.4 \mathrm{mpa}$, and the average pressure of the clutch pump body manufactured by the end face welding method was 9.6MPa.

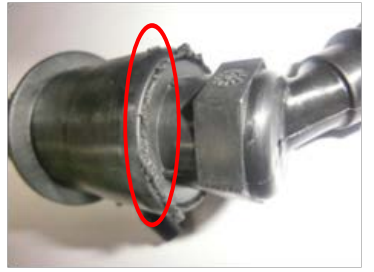

Figure 5a. The welding seam of cylindrical welding

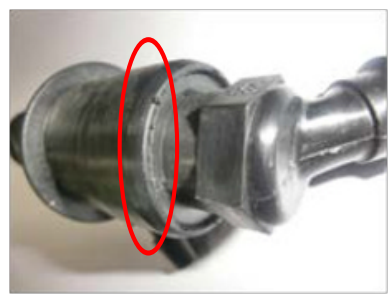

Figure $5 \mathbf{b}$. The welding seam of end face welding Figure 5. Weld condition

Through the comparative analysis and test results, it is determined that the structure of the welding surface of the upper and lower pump body is the end face welding type.

\section{Strength Analysis of Clutch Pump Body}

After completing the preliminary design of the clutch pump body, it is necessary to conduct strength analysis to check whether the clutch pump body meets the design requirements.

\subsection{Static analysis of clutch pump body}




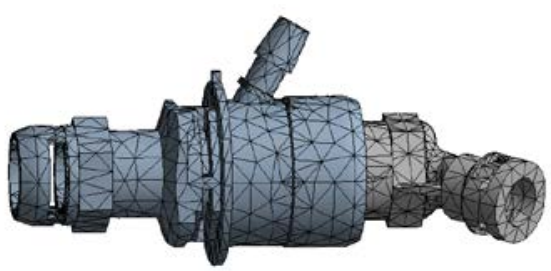

Figure 6. Simplified Model of Clutch Pump Body

The key index in the design requirements of a clutch master cylinder: it can bear 14MPa pressure. Aiming at this technical requirement, the corresponding pump body is required to meet. Therefore, it is necessary to analyze the pump body, especially pay attention to the stress condition of the welding seams. Due to the complex structures of the upper and lower pump bodies (many chamfers and fillets), the solid model of the pump body is simplified according to Saint Venant's theorem, and the simplified model of the clutch pump body is shown in Fig. 6.

\subsubsection{Meshing}

The simplified model of the pump body shown in Fig. 6 is imported into ANSYS Workbench, the material is PAMXD6, the elastic modulus and density are set according to the values in Tab. 1 , the Poisson ratio is 0.3 , and the tetrahedron mesh in the free mesh is used. The number of units is 12251, and the number of nodes is 22454.

\subsubsection{Exert constraints and boundary conditions}

In accordance with the limit condition of the automobile plastic clutch master pump, the force analysis of the pump body is carried out. On the basis of the design requirements, a uniform load of $14 \mathrm{MPa}$ (the normal working pressure is $3.5 \mathrm{Mpa}$ ) is applied on the cylindrical surface of the upper and lower pump bodies, as shown in Fig. 7. In line with the actual working condition of the clutch pump, the fixed constraint is applied to the flange surface of the upper pump body and the cylinder surface of the lower pump body (cylinder of the welding surface), as shown in Figure 7.

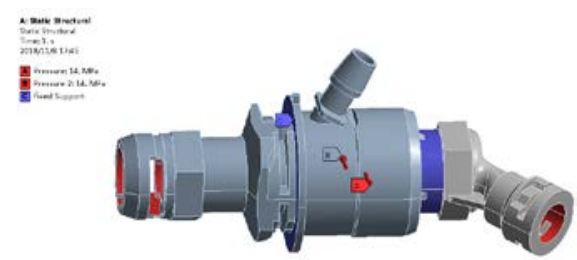

Figure 7. Distribution of fixed constraint of clutch pump body

\subsubsection{Stress and strain analysis of clutch pump body}

Fig. 8a, Fig. 8b and Fig. 8C are stress, strain and deformation diagrams of the clutch pump body respectively.

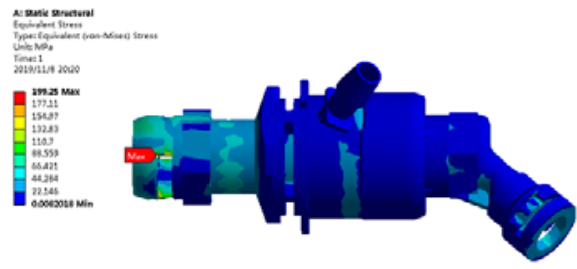

Figure 8a. Stress diagram of the clutch pump body

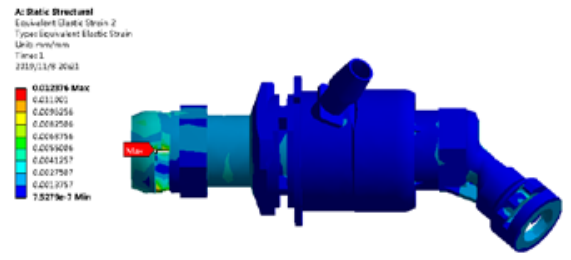

Figure 8b. Strain diagram of the clutch pump body

Figure 8. Finite Element Analysis of Clutch Pump Body

It can be seen from Fig. 8a, Fig. 8b and Fig. 9C that the stress, strain, and deformation near the welding surface are relatively small. The stress is concentrated near the port of the upper pump body. The maximum stress and strain are $199.25 \mathrm{MPa}$ and $0.01237 \mathrm{~mm}$ respectively. Because the maximum stress of the stress pump body is 199.25MPa, which is less than the allowable stress (255MPa), the pump body strength meets the design requirements.

\subsection{Static analysis of the welding seam of the}

\section{clutch pump body}

The upper pump body was removed and the lower pump body is taken as the research object to carry out the static analysis of the welding seam. The stress and strain analysis results of the pump body weld are shown in Fig. $10 \mathrm{a}$ and fig. $10 \mathrm{~b}$.

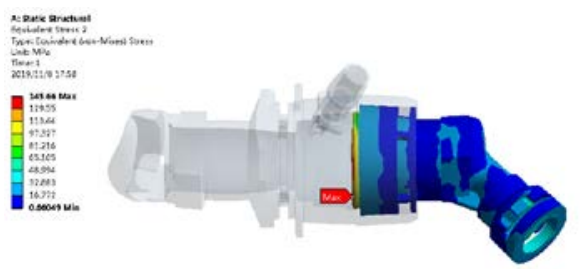

Figure 9a. Stress diagram of pump body weld

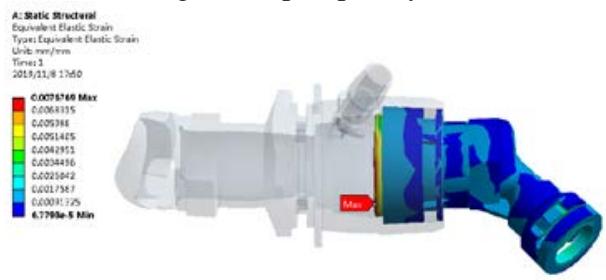

Figure 9b. Strain diagram of pump body weld

Figure 9. Stress and strain at weld of pump body

It can be seen from Fig. 9a and Fig. 9b that the maximum stress and strain occur at the weld joint of upper and lower pump bodies. The maximum stress and strain at the welding seam are $145.66 \mathrm{MPa}$ and $0.007676 \mathrm{~mm}$. Because the stress at the weld (145.66MPa) 
is less than the allowable stress of the material (204 MPa) (the allowable stress at the weld is 0.8 times of the allowable stress of the material), the weld strength meets the design requirements.

\section{Experimental Parts}

After the upper and lower pump bodies were processed by injection molding and drying $\left(120^{\circ} \mathrm{C}, 12 \mathrm{~h}\right)$, the welding parameters of the test samples are designed by the methods mentioned in literature [8], and the upper and lower pump bodies are welded in the welding equipments (EVA EGP-3p, see Fig. 2). The parameters of friction rotary welding designed in this paper are as follows: rotating speed $3000 \mathrm{r} / \mathrm{min}$, welding pressure $5 \mathrm{MPa}$ and number of turns 16r. In the light of the design requirements of the clutch pump body, pressure test, high-temperature durability test, and normal temperature durability test are carried out.

\subsection{Clutch pump body pressure test}

The pressure test equipment (Fig. 10) is used to test the maximum pressure on the clutch pump body.

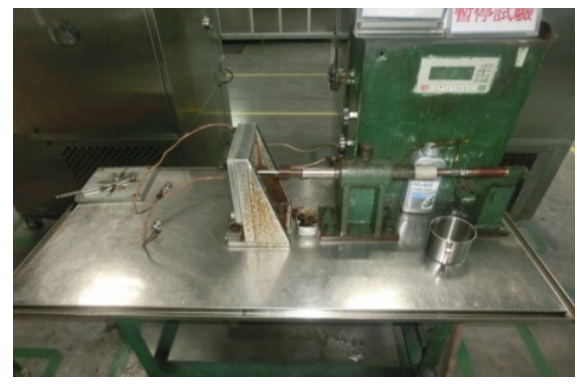

Figure 10a. Clutch pump pressure test equipment

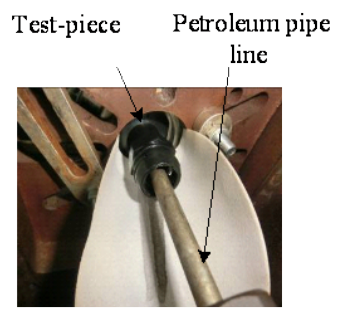

Figure 10b. Specimen test

Figure 10. High-pressure testing machine and test piece

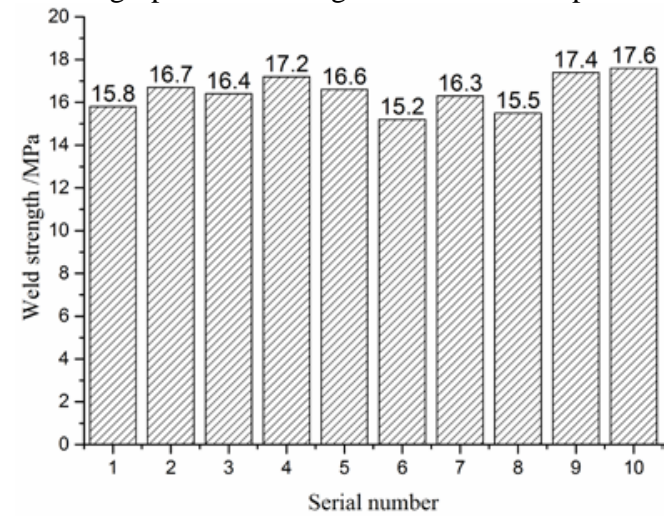

Figure 11.Welding strength of 10 groups of specimens
What can be seen from Fig. 11 is that according to the pump body structure and specified welding process proposed in this paper, the minimum pressure of 10 groups of plastic clutch pump bodies (including weld) after friction welding is $15.2 \mathrm{MPa}$, the maximum pressure is $17.6 \mathrm{MPa}$, exceeding the design requirements of $14 \mathrm{MPa}$. The test results show that the end welded upper and lower pump body structure can meet the requirements of weld strength after welding.

\subsection{Durability tests}

5 groups of test pieces are selected (the number of pieces that can be tested at the same time by the equipment is 6) and put into the high-temperature endurance test equipment with the set temperature of $100^{\circ} \mathrm{C}$ (Fig. 12), and the pressure is built with the standard circulation of $3.5 \mathrm{MPa}$ in each cylinder. After the test of 5 groups of test pieces, no oil leakage of the clutch pump body (including weld) is found when the number of cycles reaches 72870 .

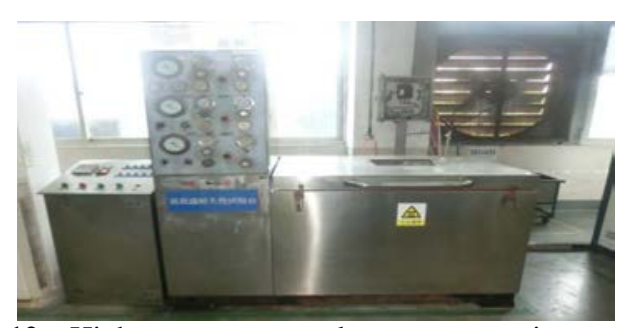

Figure 12a. High-temperature endurance test equipment

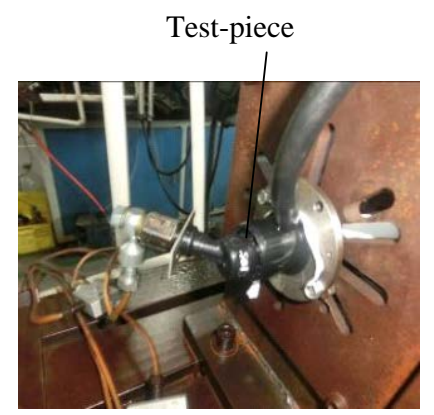

Figure 12b.Test condition of a test piece

Figure 12. High-temperature endurance test bed and test pieces

Similarly, five groups of test pieces are selected and put into the normal temperature $\left(25^{\circ} \mathrm{C}\right)$ endurance test machine (Fig. 13) to build the pressure, with the standard circulation pressure of $3.5 \mathrm{MPa}$ for each pump body. Through the test, no oil leakage of the clutch pump body (including weld) is found after the number of cycles of 5 groups of test pieces reaches 734800 .

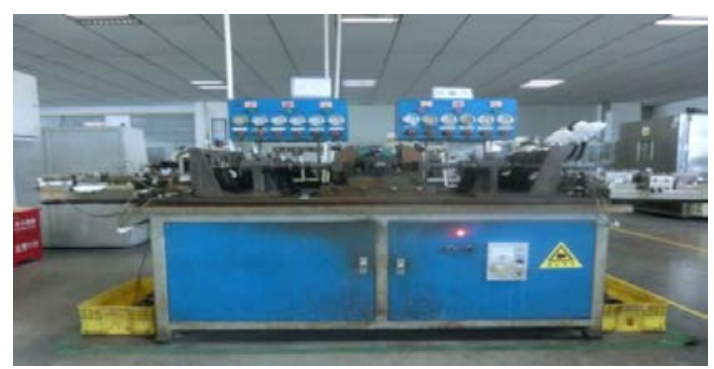

Figure 13. Room temperature durability experimental equipment 
By means of the high-temperature durability test of $100{ }^{\circ} \mathrm{C}$ and $3.5 \mathrm{Mpa}$ pressure, and the normal temperature durability test of $25^{\circ} \mathrm{C}$ and 3.5MPa pressure, the average life of the test piece is more than $7 \times 104$ times and $7 \times 105$ times respectively. The test results show that the structural design of the clutch pump body meets the design requirements.

\section{Conclusions}

Through the structural analysis and design of the master cylinder of an automobile plastic clutch, the conclusions are as follows:

1. The structure of the upper and lower clutch pump bodies with end face welding is put forward. By comparative analysis with the structural types of the upper and lower pump bodies of the cylindrical welded type in terms of welding quality, the structural type of the upper and lower pump bodies of the end face welded clutch is considered reasonable. The fact that the clutch pump body has achieved mass production fully illustrates this point.

2. By the finite element analysis, the strength of the clutch pump body and welding seam meets the technical requirements. Through the establishment of the finite element models of the pump body, the static analysis of the clutch pump body and the welding seam is carried out. The maximum stress of the pump body and the welding seam is $199.25 \mathrm{MPa}$ and $145.66 \mathrm{MPa}$ respectively, which meets the strength requirements. In addition, the stress of the upper pump body, the lower pump body, the dangerous section, and the weld under the working condition is also studied, and the results meet the first and third strength theory.

3. After testing, the pressure and durability of the clutch pump body meet the design requirements. The pressure of the trial clutch pump body (including weld) exceeds the design requirements of $14 \mathrm{MPa}$, and the number of durability test cycles at high temperature and the normal temperature reaches 72870 and 734802 respectively, which meet the design requirements.

4. The relationship between weld formation mechanism, weld shape, and weld strength needs to be studied. The next research work will focus on: the process of friction rotary welding, the process of weld formation and its influencing factors; the influence of weld size and shape on welding strength.

\section{Acknowledgments}

The authors would like to acknowledge the financial support from the Xiamen Science and Technology Project (grant No. 3502Z20179023), the Fujian Science and Technology Flatform Project (grant No. 2016BJ001), the Science\& Technology Innovation Project of Fujian Province (grant No. 2016H2003) ,and the Educational Research Project for Young Teachers in Fujian Province(grant No. JT180449).

\section{References}

1. A. H. Singh, S. Harmeet, P. Aashish, OEM's approach to the design and evaluation of plastic clamps, SAE Int. J. of Passenger Cars - Mechanical Systems , 10(1), 141-149 (2017)

2. D. J. Liang, Q. G. Deng, X. M. Wan, Optimization design of automobile plastic parts based on GRNN neural network, Plastics, 3, 98-102 (2018)

3. W. X. Zhang, H. J. Chang, Y. L. Dou, Polyurethane slush powders for instrument panel of automobiles: composition, Processing and Rheological Properties, Materials Reports, 32(24),185-190 (2018).

4. W.Hou, Y. Qian, Z. X. Su. Application of all-plastic structure of new energy vehicles in the improvement of crash safety, China Plastics Industry, 45(7),140143 (2017).

5. P. Tappe, H. Potente, New results on the spin welding of plastics, Polymer Engineering \&Science, 29(23), 1665-1660 (1989)

6. V. K. Stokes, A. J. Poslinski. Effects of variable viscosity on the steady melting of thermoplastics during spin welding, Polymer Engineering \&Science 35(5), 441-459 (1995)

7. N. L.Phadke, Spin welding, Popular Plastics \& Packaging 60(1), 30-32 (2015)

8. J. Sheng, R.Y. Xie, A design method of processing parameters of rotary friction welding for a plastic clutch pump ,China Mechanical Engineering, 30(14), 1742-1747 (2019) 